\title{
COVID 19: a clue from innate immunity
}

\section{Domenico Birra ${ }^{1}$ (D) Maurizio Benucci ${ }^{2}$. Luigi Landolfi ${ }^{3}$. Anna Merchionda ${ }^{1} \cdot$ Gabriella Loi $^{1} \cdot$ Patrizia Amato $^{4}$. Gaetano Licata $^{5} \cdot$ Luca Quartuccio $^{6}$ - Massimo Triggiani ${ }^{7} \cdot$ Paolo Moscato $^{1}$}

Published online: 10 June 2020

(C) Springer Science+Business Media, LLC, part of Springer Nature 2020

\begin{abstract}
The recent COVID-19 pandemic has had a significant impact on our lives and has rapidly expanded to reach more than 4 million cases worldwide by May 2020. These cases are characterized by extreme variability, from a mild or asymptomatic form lasting for a few days up to severe forms of interstitial pneumonia that may require ventilatory therapy and can lead to patient death.

Several hypotheses have been drawn up to understand the role of the interaction between the infectious agent and the immune system in the development of the disease and the most severe forms; the role of the cytokine storm seems important.

Innate immunity, as one of the first elements of guest interaction with different infectious agents, could play an important role in the development of the cytokine storm and be responsible for boosting more severe forms. Therefore, it seems important to study also this important arm of the immune system to adequately understand the pathogenesis of the disease. Research on this topic is also needed to develop therapeutic strategies for treatment of this disease.
\end{abstract}

Keywords COVID-19 $\cdot$ Coronavirus $\cdot$ SARS $\cdot$ Innate immunity $\cdot$ TLR $\cdot$ Interferon

\section{Introduction}

COVID-19 is an infection of a new coronavirus called severe acute respiratory syndrome coronavirus 2 (SARS-CoV-2) [1, 2] that emerged in China in late 2019 in the Wuhan region, and led to a rapid spread worldwide that has been declared a

Domenico Birra

dombirra@gmail.com

1 UOC of Internal Medicine - Rheumatology Outpatients Unit, Azienda Ospedaliero-Universitaria San Giovanni di Dio e Ruggi D'Aragona, Via San Leonardo 1, Salerno, Italy

2 Rheumatology Unit, S. Giovanni di Dio Hospital, Florence, Italy

3 UOC of Internal Medicine, Azienda Ospedaliero-Universitaria San Giovanni di Dio e Ruggi D'Aragona, Salerno, Italy

4 SERT, ASL Salerno, Salerno, Italy

5 Dermatology Unit, University of Campania Luigi Vanvitelli, Naples, Italy

6 Clinic of Rheumatology, Department of Medicine (DAME), ASUFC, University of Udine, Udine, Italy

7 Division of Allergy and Clinical Immunology, University of Salerno, Fisciano, Italy pandemic by the World Health Organization in March 2020, and now there are more than 4 million cases reported.

The SARS-CoV2 virus belongs to the coronavirus family, a positive-sense single-stranded RNA virus [3]. In vitro experiments on spike proteins of the virus hypothesized affinity with the angiotensin-converting enzyme receptor 2 (ACE2) [4, 5]; this acts as the gateway to the virus, which subsequently distributes through the circulatory stream and triggers a systemic response with hyperinflammation that has been compared to several inflammatory diseases [6]. Several studies in Chinese populations showed that the main predictors of poor prognosis are increased levels of IL6 and fibrinogen, and systemic inflammation, which contributes to mortality [7].

Different studies try to investigate how blocking inflammation can help the treatment of this pathology [8]. Researchers focused their attention on effector mechanisms; however, it is important to try to understand the role of the triggers and of innate immunity, which acting as a first defense barrier against microorganisms determines the activation of the immune response. In some subjects this response seems to be aberrant, causing immune-mediated damage in patients even more harmful than the viral damage itself. Understanding how these mechanisms act may in the future help us to create further approaches for the treatment of this disease. 


\section{Toll-like receptors}

Toll-like receptors (TLR) are proteins involved in the development and activation of innate immunity; it is a family of 11 transmembrane receptor proteins that recognize pathogenassociated molecular patterns (PAMPs) [9]. Coronavirus seems to trigger a significant cytokine release in the body, primarily IL- 6 and all the other proteins of the acute phase that leads to activation of the immune response [10]. The first mechanism of defense of human body from infections is innate immunity; in particular, the virus is recognized by specific TLR. Several studies on SARS-CoV and MERS showed the role of TLR3 in the development of a protective response against coronaviruses [11]. TLR3 is highly expressed on dendritic cells, placenta, and pancreas, and its activation, trough TRIF (TIR-domain-containing adapter-inducing interferon- $\beta$ ) pathway, determines the activation of IRF3 (interferon regulatory factor 3) and NF-kB [12, 13] (Fig.1).

In mouse models, Totura et al. demonstrate increasing levels of transcription of TLR3 after coronavirus infections already in the 2nd day post-infection; this determines activation of downstream molecules, such as TRIF, which determines the activation of transcription factors, such as IRF3 and NF-kB, associated with increased production of type I interferons (IFN alpha and beta), inflammatory cytokines (IL-6, TNF), and IFN-gamma [11]. Despite the role in the production of inflammatory cytokines, knock-out mice for TLR3 do not have reduced expression of IL6, IFN beta, TNF, and inflammatory cytokines. So several pathways linked to TLR signaling can contribute to the production of cytokines, which convey downstream on the same inflammatory cascade, with consequent amplification [12-15].

On the other side, neutralization of adaptor proteins leads to different results: the main adaptor proteins involved in TLR pathways in coronavirus infection are TRIF and MyD-88 (myeloid differentiation primary response 88 ). TRIF is associated with TLR 3 and determines the activation of IFR3 and NK$\mathrm{kB}$, while Myd-88 interacts with TLR4 and several proteins involved in IL1 function, such as IRAK1-2 and interleukin 1 (IL1) receptor.

TRIF knock-out mice showed reduced production of inflammatory cytokines and chemokines in the first 2 days after coronavirus infection, with a subsequent increase in IFN beta production followed by a marked increase in inflammatory cytokines on day 4, while (MyD-88) knock-out mice have reduced production of inflammatory cytokines and chemokines [11].

The role of TLR 4 also seems to be interesting; usually, this receptor appears pivotal for the response to the LPS of gramnegative bacteria, and similar to TLR3 it is associated with activation of transcription factors such as NF-kB and IRF3, with an amplification effect of the inflammatory cascade of TLR3 [16, 17]. Zhou investigated acute lung damage mediated by respiratory viruses in mouse models; these studies showed that laboratory animals infected with SARS, H1N1, and other lung viruses had pulmonary damage characterized by production of oxidized phospholipids; these phospholipids cause the activation of TLR4, similar to bacterial LPS, which determines activation of MyD88 and TRIF, with consequent overproduction of inflammatory cytokines, of which IL6 represents one of the main determinants of lung damage; $\mathrm{IL}^{-/-}$mice had reduced inflammatory infiltrate and reduced lung damage compared with controls [18].

These observations, together with the evidence of increased IL6 levels in patients with COVID-19, led to hypothesize on important pathogenic role of IL6. Consequently, blocking IL6, modulating levels of this cytokine, may represent a possible treatment in severe patients [19, 20]. Tocilizumab (TCZ), a recombinant humanized monoclonal antibody that has an antagonistic effect on the IL-6 receptor used in the treatment of rheumatoid arthritis, could play a key role in the treatment of seriously ill patients with COVID-19 [21]. The first pilot study for the use of tocilizumab enrolled in China 21 patients with severe coronavirus pneumonia. This study showed that tocilizumab treatment improved body temperature, arterial oxygen saturation ( $\mathrm{SpO} 2)$, reduced C-RP (C-reactive protein), and reduced oxygen demand [21].

These preliminary results led to further development of clinical trials on the use of tocilizumab and sarilumab, another IL6 inhibitor, for the treatment of COVID-19. These preliminary encouraging data seem promising, as may lead to development of therapeutic strategies for the most severe forms.

Other TLRs, such as TLR7 and 8, showed implication in coronavirus response. Normally TLR7 recognizes singlestranded RNA in endosomes and recognizes RNA of viruses such as coronaviruses, HIV, and HCV. TLR7 is highly expressed in human plasmacytoid dendritic cells (pDCs) and B cells, although low levels of this receptor are observed in epithelial cells, keratinocytes, and hepatocytes. TLR7 binds ssRNA and activates the MyD88 pathway, with consequent activation of mitogen-activated protein kinase (MAPK) cascade, NF-kB, and other pathways. This activation increases expression of TNF-alfa, IL1beta, IL-6, IL12, and IFN-alfa.

TLR8 is expressed in myeloid cells and low levels in pDCs and similar to TLR7 localizes in endosomes. RNA degradation in endosomes causes his binding with TLR8 with consequent conformational change and activation of MyD88 with a downstream pathway similar to TLR7. [22-25].

Studies on SARS-CoV, another virus of the same family, demonstrate how some regions of the viral genome were associated, in bioinformatic models, with an immunostimulant activity of TNF-a, IL-6, and IL-12 production through TLR7 and 8 , almost 2 -fold higher than other single-strand RNA viruses [26]. All these elements, together with the interlinking of the different mechanisms of innate immunity, lead to an 
Fig. 1 Role of toll-like receptor in response to coronavirus infection. TLR4 is involved in the response triggered by oxidized phospholipids (OxPLs) induced by SARSCoV2 infection, with activation, through MyD88 and TRIF, of the production of type I Interferon and inflammatory cytokines such as IL6 and TNF. TLR3 and TLR7/8 recognize viral RNA at the endosome and through MyD88 and TRIF, activate interferon regulatory factor (IRF3 and IRF7)

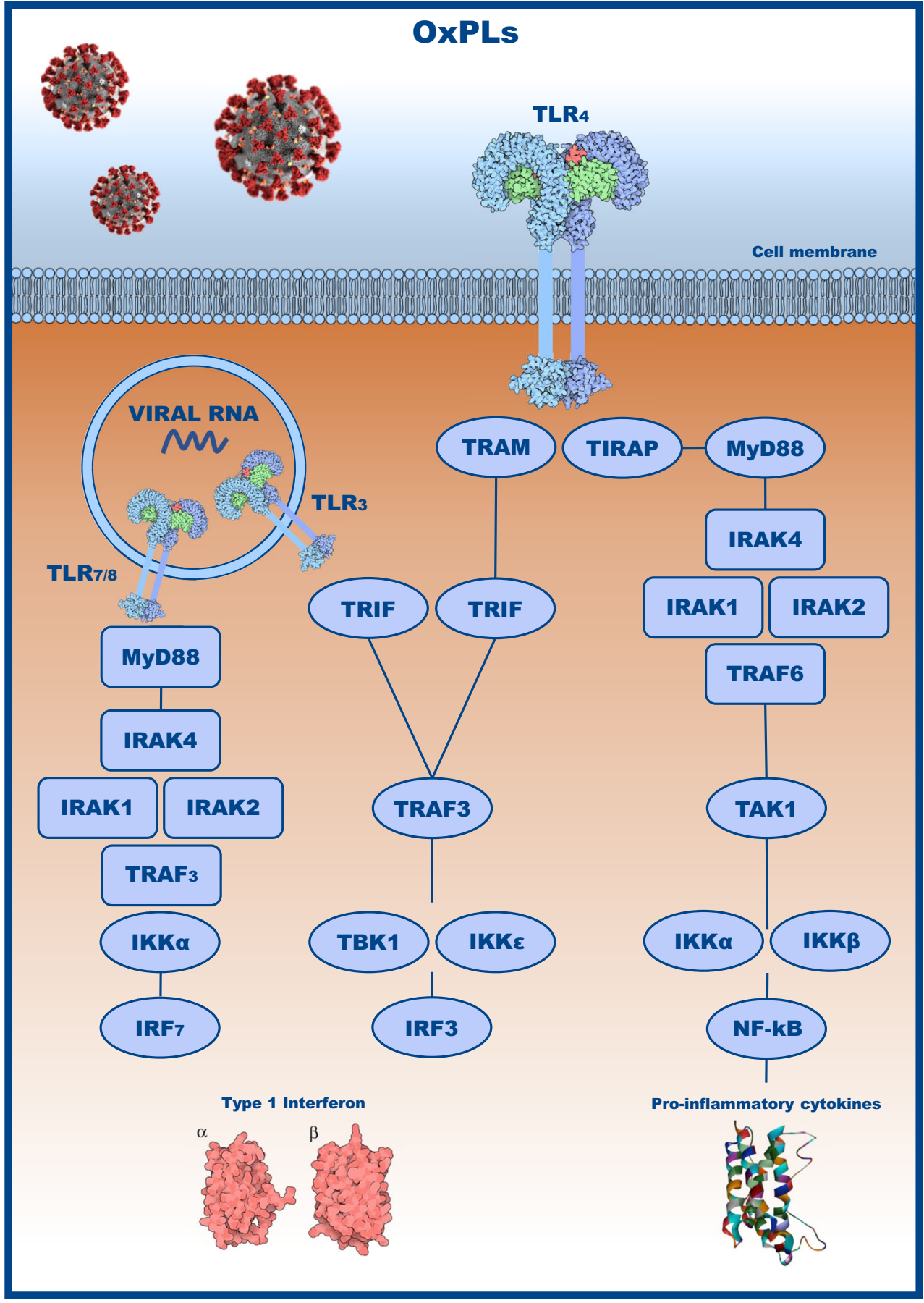

overactivation of the inflammatory response that makes coronavirus induced-pneumonia an immune-mediated disease.

\section{Complement system}

The complement system is a group of proteins present in the bloodstream in a form of inactive precursors, involved in mechanisms of protection from bacteria and viruses. The complement system acts through three different pathways: the classic pathway, the alternative pathway, and the lectin pathway, to activate different elements of the immune system [27].

The complement system appears to play an important role in coronaviruses infections. Several studies on other coronaviruses, such as SARS-CoV and MERS, demonstrate that the complement system is not directly involved in the clearance of the viruses, as $\mathrm{C} 3^{-/-}$mice do not have different viral levels compared to normal mice; however, there are more attenuated forms of lung damage. 
In the lungs of mice with a disease similar to SARS, complement deposits were abundant, with inflammatory infiltrate of lymphocytes, neutrophils, macrophages, and dendritic cells. In $\mathrm{C}^{-/-}$mice there were no differences in the lymphocytic infiltrate, but there were marked differences in neutrophils and macrophages that infiltrate with inflammatory phenotype, which were clearly reduced. This suggests that their presence could be related to local activation of the complement $[28,29]$. These findings seem important, since, in several coronavirus-mediated forms of SARS, neutrophils and macrophages play a pathogenetic role in alveolar damage, as their localization correlates with the most damaged sites of lung tissue, while lymphocytes appear crucial in postinfectious recovery, as T-cells are involved in SARS-CoV clearance and higher survival in mice and men [30, 31].

Recent preliminary data highlight the importance of complement system in patients with COVID-19 [32]. A small study showed the presence of placental complement deposits in 5 cases of pregnant patients with COVID-19, with histological evidence of avascular villi and thrombosis in fetal vessels, associated with complement deposits [33].

For these reasons, the use of complement system inhibitors for the treatment of COVID-19 has started. The first drug used was Eculizumab, a human monoclonal antibody that inhibits cleavage to C5a and C5b, involved in the generation of membrane attack complex. This structure, as a result of the activation of the complement system, creates transmembrane channels that disrupt cell membranes and lead to cell disruption and death [27]. The inhibition of this pathway through Eculizumab is a current target for the treatment of various hematological diseases. [34]

First data on the use of Eculizumab in COVID-19 come from a case series of 4 patients; after treatment, all patients clinically improved within the first $48 \mathrm{~h}$ with a reduction of inflammatory markers (Both ESR and C-RP). [35]

In addition to Eculizumab, AMY-101, a small-sized peptidic C3 inhibitor, was used to treat COVID-19 pneumonia in a single case. This drug is under development for hematological diseases and not yet approved [36]. After administration, patient clinical conditions rapidly improved after $48 \mathrm{~h}$, while leukocytosis and lymphopenia improved more slowly; these laboratory markers were associated with improvement of respiratory performance and reduction of oxygen demand. [37]

\section{Monocytes and macrophages}

The commitment of immune cells such as macrophages looks important; the first studies on autopsies in patients with COVID-19 revealed an extensive immune infiltrate consisting mainly of macrophages and monocytes, associated with neutrophils, eosinophils, and CD4 lymphocytes [38].
The role of macrophages can be inferred from the immune response observed in other coronavirus infection. SARS-CoV has an accessory protein, Open Read Frame 8 (ORF-8) [39]. This protein determines the activation of intracellular stress mechanisms, lysosomal damage, and activation of autophagy. Specifically, at a macrophage level, ORF-8 causes intracellular aggregates that interact with NLRP3, also called Cryopyrin, a structural protein of the inflammasome, determining its activation [40]. The Inflammasome is a multiprotein complex, part of the innate immune system, responsible for the activation of inflammatory response. Inflammasome activation recruits pro-caspase-1, a proteolytic enzyme that cleaves proinflammatory cytokines, such as pro-IL-1 $\beta$ and pro-IL18, thus activating them. This leads to a particular form of programmed cell death, which is called pyroptosis, in which the cell, following recognition of intracellular pathogens, undergoes programmed cell death associated with discharge of inflammatory cytokines, chemokines, and subsequent chemotaxis of inflammatory cells. In particular, the release of IL18 stimulates the production of IFN gamma, which determines the development of TH1 polarization, contributing to the development of adaptive immunity [41-46]. It is plausible that it occurs similarly in SARS-CoV-2 infection since studies on SARS-CoV-2 genome prove that there is a high analogy with the SARS-CoV ORF-8 region, so we may suppose that macrophage activation of the inflammasome plays an important role determining the important inflammatory response observed in patients with more severe forms of infection [47, 48]. Interleukin 1 release by macrophage through the inflammasome contributes to the cytokine storm responsible for the most aggressive forms of COVID-19, with symptoms of hyperactivation of the immune system similar to secondary forms of hemophagocytic lymphohistiocytosis, (sHLH) infection [49]. The pathogenetic role of IL1 could lead to important therapeutic implications. Acting on the inflammatory signaling pathway induced by the inflammasome, Anakinra, a recombinant IL-1 receptor antagonist, could block the cytokine storm, similarly to various secondary HLH conditions [50]. Several case reports evaluated the effectiveness of Anakinra in refractory forms of COVID-19 pneumonia. In a case series of 9 patients treated with subcutaneous Anakinra, there was only one case of failure, while the other 8 had improvement in clinical conditions and reduction of oxygen flow and blood inflammation markers [51]. Nowadays there are already 13 clinical trials registered on ClinicalTrials. gov investigating the efficacy of the inhibitor of IL-1-RA Anakinra alone or compared with other drugs [52].

\section{Neutrophils}

The complete blood count during COVID-19 infection is frequently performed, and an increase in neutrophils with lymphopenia is observed. However, the pathogenetic role of this 
cell population in lung disease level is still unclear [1]. From an anatomopathological point of view, some case series of patients who died from COVID-19 show a marked infiltration of neutrophils in patients' lungs [28].

However, data about the pathogenic role of neutrophils can derive from in vivo and in vitro infections from other forms of coronaviruses. In mice, lung hemorrhagic lesions follow the same distribution of the inflammatory infiltrate by polymorphonuclear cells (PMN). They also contribute to the healing process through clearance of the virus and production of growth factors involved in healing and re-epithelialization of damaged regions [29]. According to Channappanavar et al. [53], viral infection, leading to the expression of viral proteins and local damage at the epithelial cells, leads to the PMN cells infiltration. PMN cells contribute to local production of cytokines and chemokines; in particular, the interaction of PMN cells with lung cells amplifies this effect. In vitro work demonstrated that PMN cells, when they are linked with type I epithelial alveolar cells (AT1) infected with coronaviruses, had an increased expression of mRNA levels of proinflammatory cytokines (IL-18, IL-1a, IL-1b, and TNF-a), CXC chemokines (CXCL-1, CXCL-2, IP-10, and CXCL-11), and CC chemokines (CCL- 2, CCL-4, CCL-7, CCL-9, CCL-12, and CCL-22) [54]. So, their role would appear dichotomous; on the one hand, neutrophils can play as actors in the early recruitment of inflammation cells; on the other, they can contribute to tissue damage when their action does not appear to be adequately counterbalanced [55].

\section{Interferons}

Interferons (IFN) are a family of signaling proteins involved in innate and adaptive immune responses, with an important role in the inhibition of viral replication, through different effector proteins $[56,57]$. There are three types of interferons, Type I (interferon $\alpha \beta$ ), Type II (Interferon $\gamma$ ), and Type III (Interferon $\lambda$ ). Although all three are likely to be involved in protection from coronavirus infection, type I IFN is the most studied in this area and his role appears predominant especially in the early stages of the infection [58]. The production of type I IFN is enhanced by viral RNAs trough two cytosolic proteins: RIG-1 (retinoic acid-inducible gene I) and MDA5 (melanoma differentiation-associated protein 5). The recognition of viral RNA by these cytosolic receptors leads to the activation of IRF3 and determines the initiation of the transcription of type I IF, thus contributing to resolution of the infection [59].

The importance of interferon in coronavirus infections was observed in healthy volunteers; Higgins et al. [60] in the 1980s highlighted in a study on 83 healthy volunteers that intranasal administration of recombinant IFN $\alpha$ was associated with a protective effect against coronavirus infections. In particular, it was observed that in the IFN $\alpha$ treated group, both the severity of the symptoms and the nasal viral load were significantly lower, showing a marked protective effect against respiratory coronavirus.

The various members of the coronavirus family can inhibit IFN production in different ways. SARS-CoV-2 have several proteins, including nsp1, nsp3, nsp16, ORF3b, ORF6, and M and $\mathrm{N}$ proteins, similar to proteins of other coronaviruses, which act on type I IFN pathway, either by inhibiting transcription or by acting on effector mechanisms [58, 61-63]. In particular, the ability to inhibit the IFN signal varies between different family members; more aggressive family members, such as MERS-CoV and SARS-CoV, have a more marked inhibition of interferon activity, while human coronavirus HKU1, responsible for mild flu infection, has mild IFN inhibition, thus contributing to the hypothesis of how IFN attenuates viral replication and consequently reduces pathogenicity [64].

As a demonstration of the importance of the IFN, Trouillet Assant and colleagues evaluated type I IFN immunoprofiling in COVID-19 in 26 critically ill patients. They observed a peak in IFN $\alpha 2$ production after $8-10$ days of symptoms onset. A small group of patients had suppressed IFN-I production, in particular, patients with no IFN- $\alpha$ production presented poorer outcome and longer intensive care unit stay [65].

This observation has led to different clinical trials comparing the use of IFN in COVID-19 disease. Of these trials, one already completed the enrollment phase (An investigation into beneficial effects of interferon beta $1 \mathrm{a}$, compared to interferon beta $1 \mathrm{~b}$ and the base therapeutic regiment in moderate to severe COVID-19: a randomized clinical trial; ClinicalTrials. gov Identifier: NCT04343768), and others are still enrolling (ClinicalTrials.gov Identifier: NCT04320238, NCT04350671, NCT04343976, NCT04254874) [66]. Also, protective role of IFN is explored in a clinical trial (NCT04320238), developed to evaluate the effect of intranasal administration of IFN $\alpha-1 b$, alone or in combination with thymosin- $\alpha$ subcutaneous in doctors at high risk of infection [66-68].

\section{Conclusion}

Slowly we are increasing our knowledge on COVID-19; however, further studies are still needed to understand its pathophysiological and epidemiological aspects. Many notions that we have come from in vitro experiments or from other coronaviruses [47, 48]. Currently, there is still a lack of elements that allow us to predict adequately between the asymptomatic forms and the systemic form with severe lung damage. The hyperactivation of the immune system contributes significantly to the lung and systemic damage that can lead to patients' death $[62,63]$. Innate immunity, acting as the first 
element of defense, can represent, together with other mechanisms, a promising target for the treatment of patients or at least to better understand the pathogenesis of the disease.

Data availability All data are available upon request to the corresponding author.

\section{Compliance with ethical standards}

Conflict of interest The authors declare that they have no conflict of interest.

Consent for publication All authors gave their consent for the publication of the present version of the manuscript.

\section{References}

1. Guan WJ, Ni ZY, Hu Y, et al. Clinical characteristics of coronavirus disease 2019 in China [published online ahead of print, 2020. N Engl J Med. 2020;https://doi.org/10.1056/NEJMoa2002032.

2. Zhu N, Zhang D, Wang W, Li X, Yang B, Song J, et al. A novel coronavirus from patients with pneumonia in China, 2019. N Engl J Med. 2020;382(8):727-33. https://doi.org/10.1056/ NEJMoa2001017.

3. Khan S, Siddique R, Shereen MA, et al. The emergence of a novel coronavirus (SARS-CoV-2), their biology and therapeutic options [published online ahead of print, 2020 Mar 11]. J Clin Microbiol. 2020;JCM.00187-20. doi:https://doi.org/10.1128/JCM.00187-20

4. Tai W, He L, Zhang X, et al. Characterization of the receptorbinding domain (RBD) of 2019 novel coronavirus: implication for development of RBD protein as a viral attachment inhibitor and vaccine [published online ahead of print, 2020 Mar 19]. Cell Mol Immunol. 2020;https://doi.org/10.1038/s41423-020-0400-4.

5. Fu Y, Cheng Y, Wu Y. Understanding SARS-CoV-2-mediated inflammatory responses: from mechanisms to potential therapeutic tools [published online ahead of print, 2020 Mar 3]. Virol Sin. 2020;https://doi.org/10.1007/s12250-020-00207-4.

6. Hoffmann M, Kleine-Weber H, Schroeder S, et al. SARS-CoV-2 cell entry depends on ACE2 and TMPRSS2 and is blocked by a clinically proven protease inhibitor [published online ahead of print, 2020 Mar 4]. Cell. 2020;S0092-8674(20)30229-4. doi:https://doi. org/10.1016/j.cell.2020.02.052

7. Ruan Q, Yang K, Wang W, Jiang L, Song J Clinical predictors of mortality due to COVID-19 based on an analysis of data of 150 patients from Wuhan, China. Intensive Care Med. 2020; (published online March 3.)

8. Sarzi-Puttini P, Giorgi V, Sirotti S, et al. COVID-19, cytokines and immunosuppression: what can we learn from severe acute respiratory syndrome? [published online ahead of print, 2020 Mar 22]. Clin Exp Rheumatol 2020;

9. Fitzgerald KA, Kagan JC. Toll-like receptors and the control of immunity. Cell. 2020;180(6):1044-66. https://doi.org/10.1016/j. cell.2020.02.041.

10. Conti P, Ronconi G, Caraffa A, et al. Induction of pro-inflammatory cytokines (IL-1 and IL-6) and lung inflammation by coronavirus-19 (COVI-19 or SARS-CoV-2): anti-inflammatory strategies [published online ahead of print, 2020 Mar 14]. J Biol Regul Homeost Agents. 2020;34(2):1. doi:https://doi.org/10.23812/CONTI-E

11. Totura AL, Whitmore A, Agnihothram S, et al. Toll-like receptor 3 signaling via TRIF contributes to a protective innate immune response to severe acute respiratory syndrome coronavirus infection.
mBio. 2015;6(3):e00638-15. Published 2015 May 26. doi:https:// doi.org/10.1128/mBio.00638-15

12. Yamamoto Y, Gaynor RB. Role of the NF-kappaB pathway in the pathogenesis of human disease states. Curr Mol Med. 2001;1(3): 287-96. https://doi.org/10.2174/1566524013363816.

13. Uematsu S, Akira S. Toll-like receptors and type I interferons. J Biol Chem. 2007;282(21):15319-23. https://doi.org/10.1074/jbc. R700009200.

14. Yamamoto M, Sato S, Hemmi H, Hoshino K, Kaisho T, Sanjo H, et al. Role of adaptor TRIF in the MyD88-independent toll-like receptor signaling pathway. Science. 2003;301(5633):640-3. https://doi.org/10.1126/science.1087262.

15. Nilsen NJ, Vladimer GI, Stenvik J, Orning MPA, Zeid-Kilani MV, Bugge $\mathrm{M}$, et al. A role for the adaptor proteins TRAM and TRIF in toll-like receptor 2 signaling. J Biol Chem. 2015;290(6):3209-22. https://doi.org/10.1074/jbc.M114.593426.

16. Piras V, Selvarajoo K. Beyond MyD88 and TRIF pathways in tolllike receptor signaling. Front Immunol. 2014;5:70. Published 2014 Feb 24. doi:https://doi.org/10.3389/fimmu.2014.00070

17. Imai Y, Kuba K, Neely GG, Yaghubian-Malhami R, Perkmann T, van Loo $\mathrm{G}$, et al. Identification of oxidative stress and toll-like receptor 4 signaling as a key pathway of acute lung injury. Cell. 2008;133(2):235-49. https://doi.org/10.1016/j.cell.2008.02.043.

18. Zhou S, Wang G, Zhang W. Effect of TLR4/MyD88 signaling pathway on sepsis-associated acute respiratory distress syndrome in rats, via regulation of macrophage activation and inflammatory response. Exp Ther Med. 2018;15(4):3376-84. https://doi.org/10. 3892/etm.2018.5815.

19. van Kraaij TD, Mostard RL, Ramiro S, et al. Tocilizumab in severe COVID-19 pneumonia and concomitant cytokine release syndrome. Eur J Case Rep Intern Med. 2020;7(5):001675. Published 2020 Apr 22. doi:https://doi.org/10.12890/2020 001675

20. Wang C, Fei D, Li X, Zhao M, Yu K. IL-6 may be a good biomarker for earlier detection of COVID-19 progression [published online ahead of print, 2020 May 8]. Intensive Care Med 2020;1-2. doi: https://doi.org/10.1007/s00134-020-06065-8.

21. Kaly L, Rosner I. Tocilizumab - a novel therapy for non-organspecific autoimmune diseases. Best Pract Res Clin Rheumatol. 2012;26(1):157-65. https://doi.org/10.1016/j.berh.2012.01.001.

22. Petes C, Odoardi N, Gee K. The toll for trafficking: toll-like receptor 7 delivery to the endosome. Front Immunol. 2017;8:1075. Published 2017 Sep 4. doi:https://doi.org/10.3389/fimmu.2017. 01075

23. Moen SH, Ehrnström B, Kojen JF, et al. Human toll-like receptor 8 (TLR8) is an important sensor of pyogenic bacteria, and is attenuated by cell surface TLR signaling. Front Immunol. 2019;10:1209. Published 2019 May 31. doi:https://doi.org/10.3389/fimmu.2019. 01209

24. Uto T, Akagi T, Yoshinaga K, Toyama M, Akashi M, Baba M. The induction of innate and adaptive immunity by biodegradable $\operatorname{poly}(\gamma$-glutamic acid) nanoparticles via a TLR4 and MyD88 signaling pathway. Biomaterials. 2011;32(22):5206-12. https://doi. org/10.1016/j.biomaterials.2011.03.052.

25. Hornung V, Barchet $\mathrm{W}$, Schlee M, Hartmann G. RNA recognition via TLR7 and TLR8. Handb Exp Pharmacol. 2008;183:71-86. https://doi.org/10.1007/978-3-540-72167-3_4.

26. Li Y, Chen M, Cao H, Zhu Y, Zheng J, Zhou H. Extraordinary GUrich single-strand RNA identified from SARS coronavirus contributes an excessive innate immune response. Microbes Infect. 2013;15(2):88-95. https://doi.org/10.1016/j.micinf.2012.10.008.

27. Sarma JV, Ward PA. The complement system. Cell Tissue Res. 2011;343(1):227-35. https://doi.org/10.1007/s00441-010-1034-0.

28. Gralinski LE, Sheahan TP, Morrison TE, et al. Complement activation contributes to severe acute respiratory syndrome coronavirus pathogenesis. mBio. 2018;9(5):e01753-18. Published 2018 Oct 9. doi:https://doi.org/10.1128/mBio.01753-18 
29. van den Brand JM, Haagmans BL, van Riel D, Osterhaus AD, Kuiken T. The pathology and pathogenesis of experimental severe acute respiratory syndrome and influenza in animal models. J Comp Pathol. 2014;151(1):83-112. https://doi.org/10.1016/j.jcpa. 2014.01.004.

30. Zhao J, Zhao J, Perlman S. T cell responses are required for protection from clinical disease and for virus clearance in severe acute respiratory syndrome coronavirus-infected mice. J Virol. 2010;84(18):9318-25. https://doi.org/10.1128/JVI.01049-10.

31. Bosmann M, Ward PA. Role of C3, C5 and anaphylatoxin receptors in acute lung injury and in sepsis. Adv Exp Med Biol. 2012;946:147-59.

32. Risitano AM, Mastellos DC, Huber-Lang M, Yancopoulou D, Garlanda C, Ciceri F, Lambris JD Complement as a target in COVID-19? [published online ahead of print, 2020 Apr 23]. Nat Rev Immunol 2020;1-2. doi:https://doi.org/10.1038/s41577-0200320-7.

33. Mulvey JJ, Magro CM, Ma LX, Nuovo GJ, Baergen RN. Analysis of complement deposition and viral RNA in placentas of COVID19 patients [published online ahead of print, $2020 \mathrm{Apr} 25]$. Ann Diagn Pathol 2020;46:151530. doi:https://doi.org/10.1016/j. anndiagpath.2020.151530.

34. Olson SR, Lu E, Sulpizio E, Shatzel JJ, Rueda JF, DeLoughery TG. When to stop Eculizumab in complement-mediated thrombotic microangiopathies. Am J Nephrol. 2018;48(2):96-107. https://doi. org/10.1159/000492033.

35. Diurno F, Numis FG, Porta G, et al. Eculizumab treatment in patients with COVID-19: preliminary results from real life ASL Napoli 2 Nord experience. Eur Rev Med Pharmacol Sci. 2020;24(7):4040-7. https://doi.org/10.26355/eurrev_202004_ 20875.

36. Lindorfer MA, Cook EM, Reis ES, Ricklin D, Risitano AM, Lambris JD, et al. Compstatin Cp40 blocks hematin-mediated deposition of $\mathrm{C} 3 \mathrm{~b}$ fragments on erythrocytes: implications for treatment of malarial anemia. Clin Immunol. 2016;171:32-5. https:// doi.org/10.1016/j.clim.2016.08.017.

37. Mastaglio S, Ruggeri A, Risitano AM, Angelillo P, Yancopoulou D, Mastellos DC, Huber-Lang M, Piemontese S, Assanelli A, Garlanda C, Lambris JD, Ciceri F The first case of COVID-19 treated with the complement C3 inhibitor AMY-101 [published online ahead of print, 2020 Apr 29]. Clin Immunol 2020;215: 108450. doi:https://doi.org/10.1016/j.clim.2020.108450.

38. Yao XH, Li TY, He ZC, et al. Zhonghua Bing Li Xue Za Zhi 2020;49(0):E009. doi:https://doi.org/10.3760/cma.j.cn112151$20200312-00193$.

39. Shi CS, Nabar NR, Huang NN, Kehrl JH. SARS-coronavirus open reading frame- $8 \mathrm{~b}$ triggers intracellular stress pathways and activates NLRP3 inflammasomes. Cell Death Discov. 2019;5:101. Published 2019 Jun 5. doi:https://doi.org/10.1038/s41420-019-0181-7

40. He Y, Hara H, Núñez G. Mechanism and regulation of NLRP3 Inflammasome activation. Trends Biochem Sci. 2016;41(12): 1012-21. https://doi.org/10.1016/j.tibs.2016.09.002.

41. Byrne BG, Dubuisson JF, Joshi AD, Persson JJ, Swanson MS. Inflammasome components coordinate autophagy and pyroptosis as macrophage responses to infection. mBio. 2013;4(1):e00620 12. Published 2013 Feb 12. doi:https://doi.org/10.1128/mBio. 00620-12

42. Channappanavar R, Fehr AR, Vijay R, Mack M, Zhao J, Meyerholz DK, et al. Dysregulated type I interferon and inflammatory monocyte-macrophage responses cause lethal pneumonia in SARS-CoV-infected mice. Cell Host Microbe. 2016;19:181-93.

43. Kaplanski G. Interleukin-18: biological properties and role in disease pathogenesis. Immunol Rev. 2018;281(1):138-53. https://doi. org/10.1111/imr.12616.
44. Hilgenfeld R, Peiris M. From SARS to MERS: 10 years of research on highly pathogenic human coronaviruses. Antivir Res. 2013;100: 286-95.

45. Muth D, Corman VM, Roth H, Binger T, Dijkman R, Gottula LT, et al. Attenuation of replication by a 29 nucleotide deletion in SARS-coronavirus acquired during the early stages of human-tohuman transmission. Sci Rep. 2018;8:15177.

46. Oostra M, de Haan CA, Rottier PJ. The 29-nucleotide deletion present in human but not in animal severe acute respiratory syndrome coronaviruses disrupts the functional expression of open reading frame 8. J Virol. 2007;81:13876-88.

47. Li J, Liu W. Puzzle of highly pathogenic human coronaviruses (2019-nCoV) [published online ahead of print, 2020 Feb 22]. Protein Cell. 2020;https://doi.org/10.1007/s13238-020-00693-y.

48. Andersen KG, Rambaut A, Lipkin WI, Holmes EC, Garry RF. The proximal origin of SARS-CoV-2. Nat Med. 2020;26:450-2. https:// doi.org/10.1038/s41591-020-0820-9.

49. Wampler Muskardin TL. Intravenous Anakinra for macrophage activation syndrome may hold lessons for treatment of cytokine storm in the setting of coronavirus disease 2019 [published online ahead of print, 2020 Apr 8]. ACR Open Rheumatol. 2020;https:// doi.org/10.1002/acr2.11140.

50. Monteagudo LA, Boothby A, Gertner E. Continuous intravenous Anakinra infusion to calm the cytokine storm in macrophage activation syndrome [published online ahead of print, 2020 Apr 8]. ACR Open Rheumatol. 2020;https://doi.org/10.1002/acr2.11135.

51. Aouba A, Baldolli A, Geffray L, et al. Targeting the inflammatory cascade with anakinra in moderate to severe COVID-19 pneumonia: case series [published online ahead of print, 2020 May 6]. Ann Rheum Dis. 2020;annrheumdis-2020-217706. doi:https://doi.org/ 10.1136/annrheumdis-2020-217706

52. Avaible from https://clinicaltrials.gov/ct2/results/details?term= Anakinra\&cond=COVID Accessed May 14, 2020.

53. Channappanavar R, Perlman S. Evaluation of activation and inflammatory activity of myeloid cells during pathogenic human coronavirus infection. Methods Mol Biol. 2020;2099:195-204. https://doi.org/10.1007/978-1-0716-0211-9_15.

54. Haick AK, Rzepka JP, Brandon E, Balemba OB, Miura TA. Neutrophils are needed for an effective immune response against pulmonary rat coronavirus infection, but also contribute to pathology. J Gen Virol. 2014;95(Pt 3):578-90. https://doi.org/10.1099/ vir.0.061986-0.

55. Funk CJ, Manzer R, Miura TA, Groshong SD, Ito Y, Travanty EA, et al. Rat respiratory coronavirus infection: replication in airway and alveolar epithelial cells and the innate immune response. J Gen Virol. 2009;90:2956-64.

56. Negishi H, Taniguchi T, Yanai H. The interferon (IFN) class of cytokines and the IFN regulatory factor (IRF) transcription factor family. Cold Spring Harb Perspect Biol. 2018;10(11):a028423.

57. Schoggins JW. Interferon-stimulated genes: what do they all do? Annu Rev Virol. 2019;6(1):567-84. https://doi.org/10.1146/ annurev-virology-092818-015756.

58. Fensterl V, Chattopadhyay S, Sen GC. No love lost between viruses and Interferons. Annu Rev Virol. 2015;2(1):549-72. https://doi. org/10.1146/annurev-virology-100114-055249.

59. Wong LY, Lui PY, Jin DY. A molecular arms race between host innate antiviral response and emerging human coronaviruses. Virol Sin. 2016;31:12-23.

60. Gale M Jr. Looking forward in interferon and cytokine research: defining effector genes of interferon and cytokine actions. J Interf Cytokine Res. 2018;38(6):235. https://doi.org/10.1089/jir.2018. 29008.mgj.

61. Higgins PG, Phillpotts RJ, Scott GM, Wallace J, Bernhardt LL, Tyrrell DA. Intranasal interferon as protection against experimental respiratory coronavirus infection in volunteers. Antimicrob Agents 
Chemother. 1983;24(5):713-5. https://doi.org/10.1128/aac.24.5. 713.

62. Volk A, Hackbart M, Deng X, Cruz-Pulido Y, O'Brien A, Baker $\mathrm{SC}$. Coronavirus endoribonuclease and deubiquitinating interferon antagonists differentially modulate the host response during replication in macrophages [published online ahead of print, 2020 Mar 18]. J Virol. 2020;JVI.00178-20. doi:https://doi.org/10.1128/JVI. 00178-20

63. Siu KL, Kok KH, Ng MH, et al. Severe acute respiratory syndrome coronavirus $\mathrm{M}$ protein inhibits type I interferon production by impeding the formation of TRAF3.TANK.TBK1/IKK $\varepsilon$ complex. J Biol Chem. 2009;284:16202-9.

64. Lui PY, Wong LY, Fung CL, et al. Middle East respiratory syndrome coronavirus $\mathrm{M}$ protein suppresses type I interferon expression through the inhibition of TBK1-dependent phosphorylation of IRF3. Emerg Microbes Infect. 2016;5(4):e39. Published 2016 Apr 20. doi:https://doi.org/10.1038/emi.2016.33

65. Fung SY, Yuen KS, Ye ZW, Chan CP, Jin DY. A tug-of-war between severe acute respiratory syndrome coronavirus 2 and host antiviral defence: lessons from other pathogenic viruses. Emerg Microbes Infect. 2020;9(1):558-570. Published 2020 Mar 14. doi: https://doi.org/10.1080/22221751.2020.1736644

66. Trouillet-Assant S, Viel S, Gaymard A, et al. Type I IFN immunoprofiling in COVID-19 patients [published online ahead of print, 2020 Apr 29]. J Allergy Clin Immunol. 2020;S00916749(20)30578-9. doi:https://doi.org/10.1016/j.jaci.2020.04.029

67. Xu X, Han M, Li T, Sun W, Wang D, Fu B, Zhou Y, Zheng X, Yang Y, Li X, Zhang X, Pan A, Wei H Effective treatment of severe COVID-19 patients with tocilizumab [published online ahead of print, 2020 Apr 29]. Proc Natl Acad Sci U S A 2020;202005615. doi:https://doi.org/10.1073/pnas.2005615117, 10970, 10975.

68. https://clinicaltrials.gov/ct $2 /$ results/details?term=Interferon\&cond= COVID19 Accessed May 14, 2020.

Publisher's note Springer Nature remains neutral with regard to jurisdictional claims in published maps and institutional affiliations. 